\title{
Peroxisomal polyamine oxidase and NADPH-oxidase cross-talk for ROS homeostasis which affects respiration rate in Arabidopsis thaliana
}

\author{
Efthimios A. Andronis ${ }^{1}$, Panagiotis N. Moschou ${ }^{2}$, Imene Toumi ${ }^{1}$ and Kalliopi A. Roubelakis-Angelakis ${ }^{1}{ }^{*}$ \\ ' Laboratory of Plant Physiology and Biotechnology, Department of Biology, University of Crete, Heraklion, Greece \\ 2 Department of Plant Biology, Uppsala BioCenter, Swedish University of Agricultural Sciences and Linnean Center for Plant Biology, Uppsala, Sweden
}

\section{Edited by: \\ Antonio F. Tiburcio, Universitat de \\ Barcelona, Spain}

\section{Reviewed by:}

Igor Pottosin, Universidad de Colima Mexico

Ruben Alcazar, Universitat de

Barcelona, Spain

\section{${ }^{*}$ Correspondence:}

Kalliopi A. Roubelakis-Angelakis,

Laboratory of Plant Physiology and Biotechnology, Department of

Biology, University of Crete, Voutes University Campus, Heraklion,

Crete 70013, Greece

e-mail:poproube@biology.uoc.gr

\begin{abstract}
Homeostasis of reactive oxygen species (ROS) in the intracellular compartments is of critical importance as ROS have been linked with nearly all cellular processes and more importantly with diseases and aging. PAs are nitrogenous molecules with an evolutionary conserved role in the regulation of metabolic and energetic status of cells. Recent evidence also suggests that polyamines (PA) are major regulators of ROS homeostasis. In Arabidopsis the backconversion of the PAs spermidine (Spd) and spermine to putrescine and Spd, respectively, is catalyzed by two peroxisomal PA oxidases (AtPAO). However, the physiological role of this pathway remains largely elusive. Here we explore the role of peroxisomal PA backconversion and in particular that catalyzed by the highly expressed AtPAO3 in the regulation of ROS homeostasis and mitochondrial respiratory burst. Exogenous PAs exert an NADPH-oxidase dependent stimulation of oxygen consumption, with Spd exerting the strongest effect. This increase is attenuated by treatment with the $\mathrm{NADPH}$-oxidase blocker diphenyleneiodonium iodide (DPI). Loss-of-function of AtPAO3 gene results to increased NADPH-oxidase-dependent production of superoxide anions $\left(\mathrm{O}_{2}^{\bullet-}\right)$, but not $\mathrm{H}_{2} \mathrm{O}_{2}$, which activate the mitochondrial alternative oxidase pathway (AOX). On the contrary, overexpression of AtPAO3 results to an increased but balanced production of both $\mathrm{H}_{2} \mathrm{O}_{2}$ and $\mathrm{O}_{2}^{\bullet-}$. These results suggest that the ratio of $\mathrm{O}_{2}^{\bullet-} / \mathrm{H}_{2} \mathrm{O}_{2}$ regulates respiratory chain in mitochondria, with PA-dependent production of $\mathrm{O}_{2}^{\bullet-}$ by NADPH-oxidase tilting the balance of electron transfer chain in favor of the AOX pathway. In addition, AtPAO3 seems to be an important component in the regulating module of ROS homeostasis, while a conserved role for PA backconversion and ROS across kingdoms is discussed.
\end{abstract}

Keywords: polyamines, NADPH-oxidase, polyamine oxidases, respiration, ROS homeostasis, Arabidopsis

\section{INTRODUCTION}

Polyamines (PA) are low-molecular mass nitrogenous compounds, and the most abundant ones, across kingdoms, are putrescine (Put), spermidine (Spd), spermine (Spm), and thermospermine (t-Spm); they have been correlated with plethora of biological processes, including protein regulation (Baron and Stasolla, 2008; Takahashi and Kakehi, 2010), development (Wimalasekera et al., 2011; inter alia), ion channels (Wu et al., 2010; ZepedaJazo et al., 2011), control of nitrogen: carbon balance (Mattoo et al., 2006; for review see Moschou et al., 2012), stress responses (Alcazar et al., 2011b; Marco et al., 2011; Moschou and RoubelakisAngelakis, 2013) and in particular homeostasis of reactive oxygen species (ROS; Chattopadhyay et al., 2006; inter alia).

Polyamines catabolism is mediated mainly by two classes of amine oxidases $(\mathrm{AO})$, the diamine oxidases $(\mathrm{DAO})$ and the PA oxidases (PAO; reviewed in Moschou et al., 2012). In Arabidopsis, the AO pathway consists of several, perhaps functionally redundant genes. For example, Arabidopsis has at least $10 \mathrm{DAO}$ genes (four have been characterized; Møller and McPherson, 1998; PlanasPortell et al., 2013) and five $P A O$ genes (AtPAO1-AtPAO5, all have been characterized; Ahou et al., 2014). DAOs oxidize Put and cadaverine (Cad), and with much lower affinity, Spd and Spm. The action of DAOs on Put yields pyrroline, $\mathrm{H}_{2} \mathrm{O}_{2}$, and ammonia $\left(\mathrm{NH}^{4+}\right.$; Cohen, 1998).

In contrast to DAOs, PAOs oxidize Spd, and Spm but not Put (Angelini et al., 2010). The apoplastic PAO catalyzes the terminal oxidation of PAs, yielding pyrroline and 1-(3-aminopropyl) pyrrollinium from Spd and Spm, respectively, along with 1,3diaminopropane and $\mathrm{H}_{2} \mathrm{O}_{2}$. The plant intracellular (cytoplasmic or peroxisomal) PAOs interconvert PAs, producing $\mathrm{H}_{2} \mathrm{O}_{2}$. Interestingly, they interconvert Spm to Spd and Spd to Put, reversing the PA biosynthetic pathway (Tavladoraki et al., 2006; KamadaNobusada et al., 2008; Moschou et al., 2008c; Toumi et al., 2010; Fincato et al., 2012).

Polyamines catabolism has been correlated with numerous processes including cell growth, development, stress responses, and programmed cell death (PCD; Møller and McPherson, 1998; Yoda etal., 2003, 2006; Paschalidis and Roubelakis-Angelakis, 2005a,b; Tisi etal., 2011; Moschou etal., 2012; Moschou and Roubelakis-Angelakis, 2013). We have documented the contribution of tobacco apoplastic PAO (Moschou et al., 2008b) and peroxisomal (Wu et al., 2010) AtPAO3 in $\mathrm{H}_{2} \mathrm{O}_{2}$ production. The 
apoplastic pathway has been mostly correlated with the execution of PCD (Yoda et al., 2003, 2006; Moschou et al., 2008b; Fincato et al., 2012; Moschou and Roubelakis-Angelakis, 2013). The peroxisomal AtPAO3 is critical for the elongation of pollen tube by modulating a plasma membrane $\mathrm{H}_{2} \mathrm{O}_{2}$-dependent $\mathrm{Ca}^{2+}$-influx channel (Wu et al., 2010). In Arabidopsis, PA oxidation is mediated by PAO with diverse specificities and expression patterns (Fincato et al., 2011), thereby regulating ROS levels in a complex manner.

Superoxides $\left(\mathrm{O}_{2}^{\bullet-}\right)$ and $\mathrm{H}_{2} \mathrm{O}_{2}$ are the most well studied ROS; they are important players in physiological and pathological processes (Pitzschke etal., 2006; Dikalov etal., 2011; Suzuki et al., 2013). NADPH-oxidase catalyzes the conversion of molecular oxygen to $\mathrm{O}_{2}^{\bullet-}$, and its activation accounts mostly for the large consumption of oxygen that characterizes the respiratory burst in mammalian phagocytic cells (Vignais, 2002). In mammals NADPH-oxidase is composed of membrane-bound and cytosolic proteins. In the center of the NADPH oxidase complex lies the heterodimeric NADPH-binding flavocytochrome b558, consisting of the glycosylated transmembrane protein gp91phox and the non-glycosylated p22phox subunit. Upon activation, the cytosolic proteins p47phox and p67phox become phosphorylated and translocate, together with p40phox and p21rac, to the membrane components, to form the active NADPH-oxidase complex (Segal and Abo, 1993). Plants deficient in gp91phox homologs have compromised responses to stress and have a reduced ability to accumulate ROS. Antisense tomato lines (Lerboh1) show reduced ROS accumulation and compromise wound response (Sagi et al., 2004). Arabidopsis plants disrupted in the gp91phox homologs, the respiratory burst oxidase homolog D (AtrbohD) and AtrbohF, exhibit reduced ROS production and treatment with the avirulent bacterium Pseudomonas syringae pv tomato DC3000 results to cell death (Torres et al., 2005), whereas they have diminished stomatal closure in response to abscissic acid (ABA; Kwak et al., 2003). These data suggest that NADPH-oxidase homologs in plants are important for ROS accumulation.

Another important source of ROS is the mitochondrial electron transport chain (ETC; Muller et al., 2004; Vacca et al., 2004). It consists of four complexes, tightly bound to the intermembrane space of mitochondria. Electrons derived from the tricarboxylic acid (TCA) cycle in the matrix move toward the ETC and in turn pass through the four complexes. Transfer of electrons between complex 3 and 4 of the ETC is facilitated via the electron carrier cytochrome-c (cyt-c pathway). The electron motion generates a proton gradient which in turn drives an ATPase. Dysfunction of the mitochondrial ETC leads to the leakage of electrons toward oxygen resulting in the generation of $\mathrm{O}_{2}^{\bullet-}$ (Muller et al., 2004). In order to dissipate the excess electrons, the mitochondria possess another pathway, the alternative pathway, which depends on an alternative terminal oxidase (AOX; Atkin et al., 2002). AOX alleviates mitochondrial ETC from the excess electron load (Yip and Vanlerberghe, 2001).

Previous work from our lab suggested that a regulatory crosstalk between PAs and NADPH-oxidase takes place during tobacco protoplast regeneration (Papadakis and Roubelakis-Angelakis, 2005). PAs seem to be necessary for protoplasts to retain their totipotent state, and prevention of PCD. The interaction between main cellular sources of ROS, such as mitochondria and NADPH-oxidases, however, remains obscure. More importantly, a feed-forward regulation of different ROS sources has been reported (Dikalov et al., 2011). Therefore, the regulatory crosstalk between ROS sources merits further examination.

Here, we report that exogenous PAs stimulate oxygen consumption in Arabidopsis in an NADPH-oxidase dependent manner. Plants overexpressing the peroxisomal AtPAO3 show decreased oxygen consumption rate, in strict contrast to lossof-function Atpao3 plants which show increased consumption through the AOX pathway. Surprisingly, this increase is attenuated by diphenyleneiodonium iodide (DPI) but not by ascorbate (ASA), suggesting that NADPH-oxidase is upstream of a respiratory increase mediated by AOX. By delving the regulatory function of $\mathrm{O}_{2}^{\bullet-}$ in oxygen consumption rate, we found that AtPAO3 overexpressing plants show a balanced production of both $\mathrm{O}_{2}^{\bullet-}$ and $\mathrm{H}_{2} \mathrm{O}_{2}$, while Atpao3 loss-of-function plants show a high ratio of $\mathrm{O}_{2}^{\bullet-}$ versus $\mathrm{H}_{2} \mathrm{O}_{2}$ production. These data suggest that NADPH-oxidase and AtPAO3 cross-talk for balancing intracellular $\mathrm{O}_{2}^{\bullet-} / \mathrm{H}_{2} \mathrm{O}_{2}$ which in turn affect the cyt-c/AOX pathways.

\section{MATERIALS AND METHODS PLANT MATERIAL AND GROWTH CONDITIONS}

Arabidopsis thaliana wild type (WT) plants of the ecotype Columbia (Col-0) were used along with transgenic plants overexpressing the peroxisomal AtPAO3 (S-AtPAO3) and Atpao3 T-DNA loss-of-function insertional mutants, previously described (Moschou et al., 2008c; Wu et al., 2010; Fincato et al., 2011). Plants were grown in a cabinet using an $8 / 16 \mathrm{~h}$ (light/dark) photoperiod and a constant temperature of $23^{\circ} \mathrm{C}$. Developing seedlings were transferred to 96-well plates filled with 1/4 strength Murashige and Skoog (MS; Murashige and Skoog, 1962) culture medium. All treatments were carried out by supplementing the culture medium with the corresponding agent. More specifically, the PAs Put, Spd, and Spm were added as aqueous solutions at a final concentration of $1 \mathrm{mM}$. Control plants were mock treated with $\mathrm{dH}_{2} \mathrm{O}$.

\section{POLAROGRAPHIC MEASUREMENT OF RESPIRATORY OXYGEN CONSUMPTION}

The rate of oxygen consumption was essentially determined as previously described (Andronis and Roubelakis-Angelakis, 2010). In brief, polarography was performed at $30^{\circ} \mathrm{C}$ with a Clark type electrode system (Hansatech Instruments, Kings's Lynn, Norfolk, $\mathrm{UK}$ ), in the presence and absence of the alternative respiratory inhibitor salicylhydroxamic acid (SHAM). Oxygen consumption was measured for a period of $5 \mathrm{~min}$. For inhibitor treatments, leaves were incubated in $15 \mathrm{mM}$ SHAM in 3\% (v/v) methanol for a period of $10 \mathrm{~min}$ prior to measurement. Control leaves were incubated in $\mathrm{dH}_{2} \mathrm{O}$ or $3 \%(\mathrm{v} / \mathrm{v})$ methanol. In all cases, the rate of oxygen consumption was expressed as per $\mathrm{g}$ fresh weight.

\section{NADPH OXIDASE NATIVE PAGE AND ACTIVITY STAINING}

Separation of NADPH oxidase isoenzymes and activity staining were carried out according to Carter et al. (2007). Arabidopsis leaf 
tissue was collected and ground using liquid $\mathrm{N}_{2}$. The powder was homogenized in a buffer containing $50 \mathrm{mM}$ sodium phosphate, $\mathrm{pH}$ 6.8, supplemented with $0.5 \%$ (v/v) Triton X-100. $100 \mu \mathrm{g}$ of protein were separated using native PAGE at $40 \mathrm{~mA}$. Gels were then incubated in $0.5 \mathrm{mg} \mathrm{mL}^{-1}$ nitroblue tetrazolium (NBT) in $10 \mathrm{mM}$ Tris, $\mathrm{pH} 7.4$, and $134 \mathrm{mM}$ NADPH until bands were detected.

\section{IN SITU DETECTION OF $\mathrm{H}_{2} \mathrm{O}_{2}$ AND $\mathrm{O}_{2}^{--}$}

In situ accumulation of $\mathrm{H}_{2} \mathrm{O}_{2}$ was detected using the method of Thordal-Christensen et al. (1997) and of $\mathrm{O}_{2}^{\bullet-}$ according to Jabs et al. (1996). Arabidopsis seedlings were destained using boiling pure ethanol and photographed using a Nikon Coolpix 4500 digital camera.

\section{PROTEIN GEL BLOT ANALYSES AND IN-GEL ACTIVITIES OF APX AND SOD}

Protein extractions and gel blots were performed as previously described (Moschou et al., 2013). One hundred mg of leaf material was mixed with $100 \mu \mathrm{L}$ of urea extraction buffer [4 M urea, $100 \mathrm{mM}$ DTT, and 1\% (v/v) Triton X-100] and incubated in ice for $10 \mathrm{~min}$. The samples were boiled with Laemmli sample buffer for $10 \mathrm{~min}$ and centrifuged at $13,000 \mathrm{rpm}$ for $15 \mathrm{~min}$. Equal amounts of the supernatants were loaded on $10 \%(\mathrm{v} / \mathrm{v})$ polyacrylamide gels and blotted on a polyvinylidene difluoride (PVDF) membrane.

For the activity staining of ascorbate peroxidase (APX), $10 \mathrm{mM}$ ASA were added to isoelectric focusing electrophoresis buffer (Rao et al., 1995), and 10\% gels were pre-run for $30 \mathrm{~min}$ at $20 \mathrm{~mA}$. Subsequently, the gels were incubated in the dark in a solution containing $50 \mathrm{mM}$ potassium phosphate buffer, $\mathrm{pH}$ 7.0, and $2 \mathrm{mM}$ ASA; the gels were incubated in the dark for another $30 \mathrm{~min}$ in $50 \mathrm{mM}$ potassium phosphate buffer, $\mathrm{pH} 7.0,4 \mathrm{mM}$ ASA, and $2 \mathrm{mM} \mathrm{H}_{2} \mathrm{O}_{2}$. Bands were visualized after the incubation of gels in coloring solution ( $50 \mathrm{mM}$ potassium phosphate buffer, $\mathrm{pH} 7.8$, $14 \mathrm{mM}$ tetramethylethylenediamine, TEMED; and $1.2 \mathrm{mM} \mathrm{NBT}$ ). The activity staining of superoxide dismutase (SOD) has been previously described (Beauchamp and Fridovich, 1971).

\section{IMAGE AND STATISTICAL ANALYSIS}

The image analysis was performed using ImageJ v 1.41 software $^{1}$. Statistical analysis was performed with SPSS v14 ${ }^{2}$ or JMP v 9 software $^{3}$. We used Dunett's test with alpha values set at $\alpha=0.1$.

\section{RESULTS \\ EXOGENOUS PAs STIMULATE OXYGEN CONSUMPTION RATE}

Our previous work established the effect of abiotic stress on the respiratory activity of WT tobacco plants (Andronis and Roubelakis-Angelakis, 2010). Under abiotic stress conditions, cytc, an electron carrier located between complexes III and IV of the ETC, dissociates leading to malfunction of the mitochondrial ETC and accumulation of ROS. As a result, the AOX pathway is activated in order to dissipate the excess electrons "leaking" from the ETC. Taking into consideration the link between PAs and plant

\footnotetext{
${ }^{1}$ http://rsb.info.nih.gov/ij/index.html

${ }^{2}$ www.spss.com

${ }^{3}$ www.jmp.com
}

responses to stresses, we attempted to reveal a potential correlation between PAs and respiratory activity in Arabidopsis thaliana.

Two-week old Col-0 Arabidopsis seedlings were treated with exogenous Put, Spd, and Spm and oxygen consumption rate was determined 10 min post-treatment. Respiration rate increased in the presence of all PAs used, in terms of oxygen consumption. Spd exerted the strongest effect on the respiration rate, resulting in a 2.6-fold increase compared to the mock treated plants (Figure 1). Put and Spm increased respiration, by 1.8- and 2.1fold, respectively, compared to mock treated plants. These findings revealed an apparent link between PAs and ETC regulation in plants.

\section{STIMULATION OF OXYGEN CONSUMPTION RATE DEPENDS ON PA- INDUCED GENERATION OF O $\mathrm{O}_{2}^{--}$}

Previously, we have shown that exogenous application of Spd to tobacco plants leads to a significant increase in $\mathrm{H}_{2} \mathrm{O}_{2}$ content generated by the action of PAO (Moschou et al., 2008b). A plausible hypothesis could be that $\mathrm{PAO}$-dependent ROS production is a component of the pathway which is responsible for the observed increase of the oxygen consumption rate. To test this hypothesis, we firstly examined whether exogenous Spd could induce $\mathrm{H}_{2} \mathrm{O}_{2}$ and $\mathrm{O}_{2}^{\bullet-}$ accumulation in Arabidopsis. To this end, we employed in situ detection protocols of $\mathrm{H}_{2} \mathrm{O}_{2}$ and $\mathrm{O}_{2}^{\bullet-}$. Indeed, a $10 \mathrm{~min}$ treatment with exogenous Spd $(1 \mathrm{mM})$ led to a significant accumulation of $\mathrm{H}_{2} \mathrm{O}_{2}$, as a result of PA oxidation. The use of $1 \mathrm{mM}$ Spd was based on our previous findings that this concentration is enough to enter peroxisomes and be backconverted to Put in Arabidopsis (Fincato et al., 2011). Surprisingly, we found a significant increase in $\mathrm{O}_{2}^{\bullet-}$ content, as well (Figures 2A,B). From the aforementioned it is evident that the increase in plant respiration coincided with elevated $\mathrm{H}_{2} \mathrm{O}_{2}$ and/or $\mathrm{O}_{2}^{\bullet-}$ in treated plants.

To prove the link between the produced ROS and increased respiration, we tested whether quenching of ROS would alleviate the

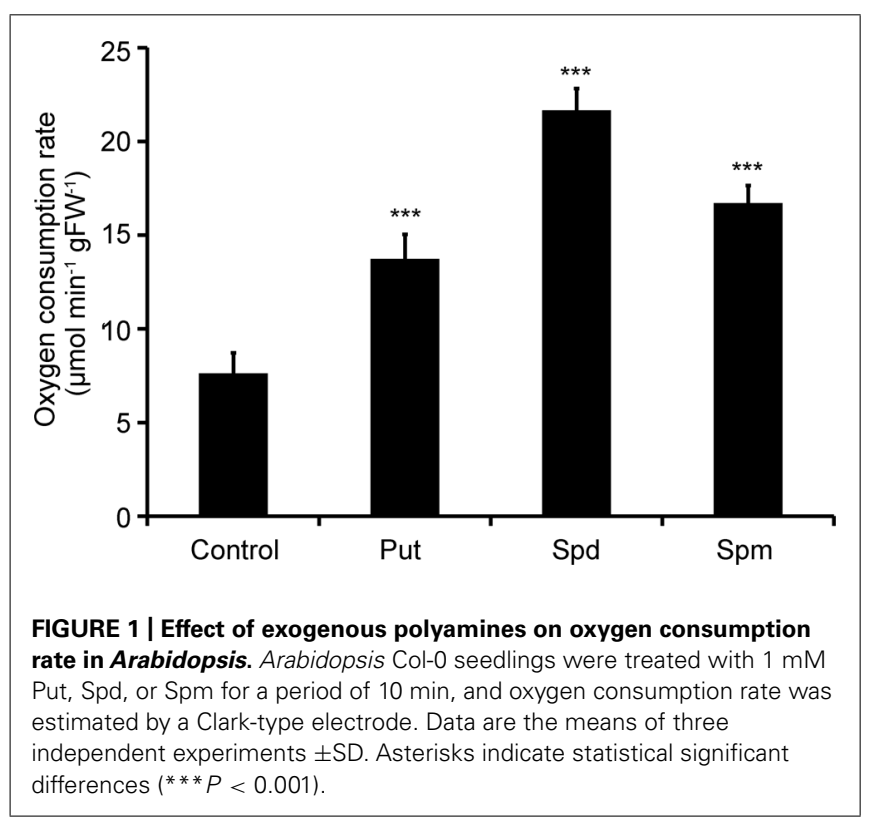




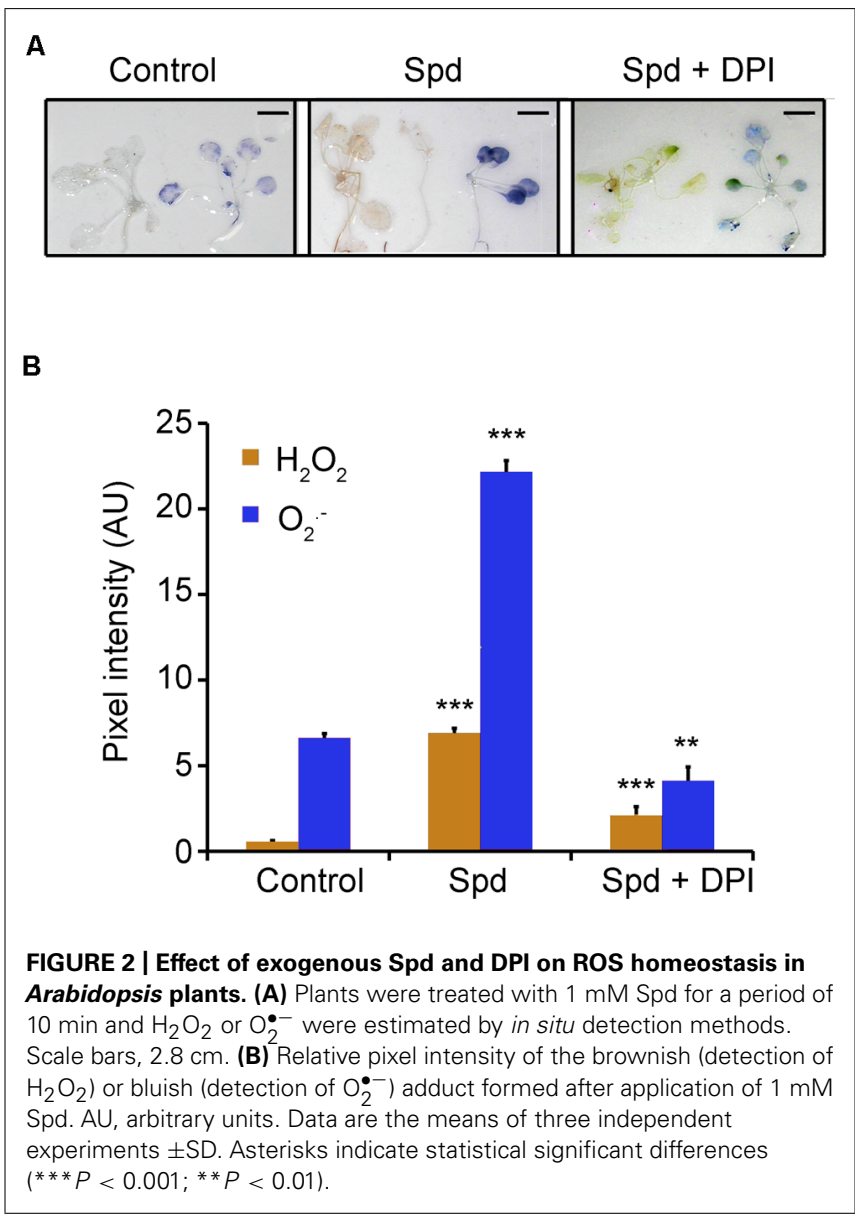

effect of Spd on respiration. Spd was added in combination with ASA, a scavenger of $\mathrm{O}_{2}^{\bullet-}$ and $\mathrm{H}_{2} \mathrm{O}_{2}$, catalase (CAT), a scavenger of $\mathrm{H}_{2} \mathrm{O}_{2}$ and SOD, a scavenger of $\mathrm{O}_{2}^{\bullet-}$. Addition of ASA to the medium failed to produce a significant effect on Spd-induced respiration, whereas CAT led to a $37 \%$ decrease over the rate found in Spd treatments (Figure 3A). The addition of SOD to the Spdcontaining medium alleviated the effect of Spd to a greater extent leading to an overall reduction of $57 \%$ over the Spd treated plants, to a rate similar to that determined for the untreated plants (control). Finally, treatment with both, SOD and CAT in addition to Spd further reduced the respiration rate, rendering it lower than that determined in the untreated plants. These results suggest that PA-dependent ROS and particularly $\mathrm{O}_{2}^{\bullet-}$ are required for induction of the increased oxygen consumption rate.

Previous work from our laboratory established the role of PAs and NADPH-oxidase in the developmental fate of isolated protoplasts (Papadakis and Roubelakis-Angelakis, 2005). Considering that Spd led to a more significant increase of $\mathrm{O}_{2}^{\bullet-}$, than of $\mathrm{H}_{2} \mathrm{O}_{2}$ we hypothesized that $\mathrm{O}_{2}^{\bullet-}$ is produced via the activation of the NADPH- oxidase. Indeed simultaneous treatment of Col0 Arabidopsis plants with Spd and the NADPH-oxidase blocker DPI led to a significant reduction in both $\mathrm{H}_{2} \mathrm{O}_{2}$ and $\mathrm{O}_{2}^{\bullet-}$ in the treated plants (Figures 2A,B), providing strong evidence for the participation of the NADPH-oxidase in the Spd-induced ROS accumulation.

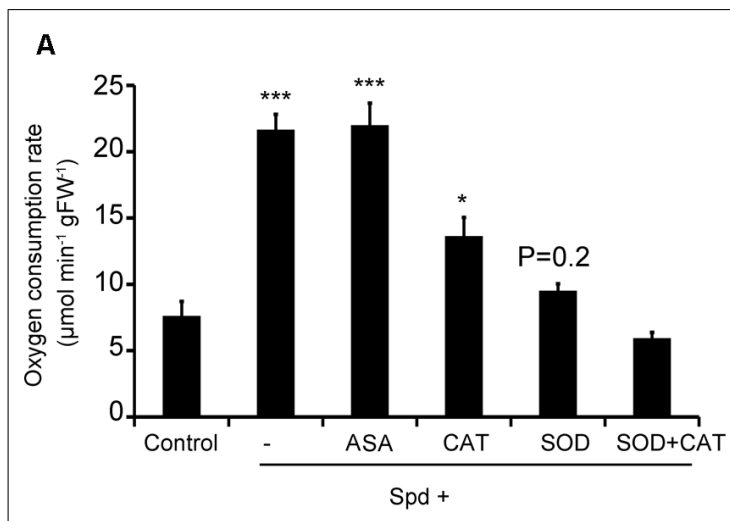

B
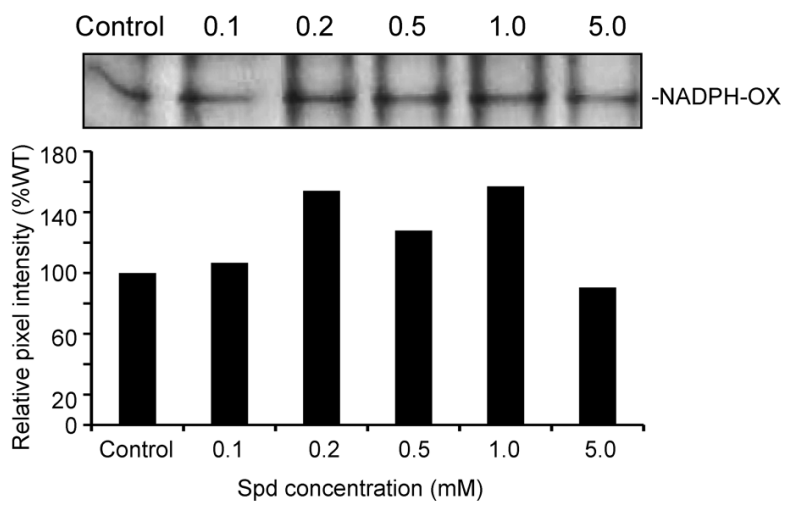

FIGURE 3 | Combined effect of exogenous Spd and ASA, CAT or SOD on oxygen consumption rate of Arabidopsis plants and dose-dependent response of NADPH-oxidase activity by Spd.

(A) Oxygen consumption rate in plants incubated in the respective medium for $10 \mathrm{~min}$. Data are the means of three independent experiments \pm SD. Asterisks indicate statistical significant differences $\left(^{* *} P<0.001\right.$; ${ }^{*} P<0.05$ ). For Spd+SOD treatment $P$ value is indicated. (B) Effect of exogenous Spd on NADPH-oxidase activity in Col-0 Arabidopsis plants. Plants were treated with $0.1,0.2,0.5,1$, and $5 \mathrm{mM}$ Spd for a period of $10 \mathrm{~min}$ and relative pixel intensity of lane profile after application of $1 \mathrm{mM}$ Spd was assessed.

So far there are strong indications that there is interplay between Spd and NADPH- oxidase in the generation of ROS which induces enhancement of respiration in Arabidopsis. To further verify this result we studied the effect of Spd as a doseresponse on NADPH-oxidase activity in Col-0 Arabidopsis plants. Treatment with a range of Spd concentrations resulted to a dose-dependent effect in the increase of NADPH-oxidase activity up to a saturation point, and decreased thereafter as indicated by an in gel enzymatic assay (Figure 3B). Lower concentrations of $\operatorname{Spd}(0.1,0.2$, and $1 \mathrm{mM})$ increased NADPH-oxidase activity compared with the control plants, whereas higher concentration ( $5 \mathrm{mM}$ and above) decreased NADPH-oxidase activity. These results suggest that low concentrations of Spd can induce NADPH-oxidase.

\section{AtPA03 REGULATES THE BALANCE BETWEEN $\mathrm{H}_{2} \mathrm{O}_{2}$ AND $\mathrm{O}_{2}^{\circ-}$}

Recent data have shed light on the biochemical role of plant intracellular PAOs, which interconvert Spm to Spd and Spd 
to Put, reversing the PA biosynthetic pathway (Fincato et al., 2011; Ahou et al., 2014). We have previously shown that plants overexpressing AtPAO3 efficiently oxidize Spd to Put producing $\mathrm{H}_{2} \mathrm{O}_{2}$ (Moschou et al., 2008c; Wu et al., 2010; Fincato et al., 2011). S-AtPAO3 plants overexpressing the peroxisomal AtPAO3 and lossof-function Atpao3 seem to be valuable tools in the study of PA-induced respiration in Arabidopsis due to the localization of AtPAO3 in the peroxisomes which are in proximity to mitochondria. Indeed, in situ detection of ROS in the S-AtPAO3 Arabidopsis plants showed that they exhibited a higher but balanced production of $\mathrm{H}_{2} \mathrm{O}_{2}$ and $\mathrm{O}_{2}^{\bullet-}$ compared with Col-0 plants (Figure 4A). In contrast, Atpao3 plants accumulated significantly lower levels of $\mathrm{H}_{2} \mathrm{O}_{2}$ when compared with Col-0 plants, but increased levels of $\mathrm{O}_{2}^{\bullet-}$. Therefore, S-AtPAO3 and Atpao3 plants are good models
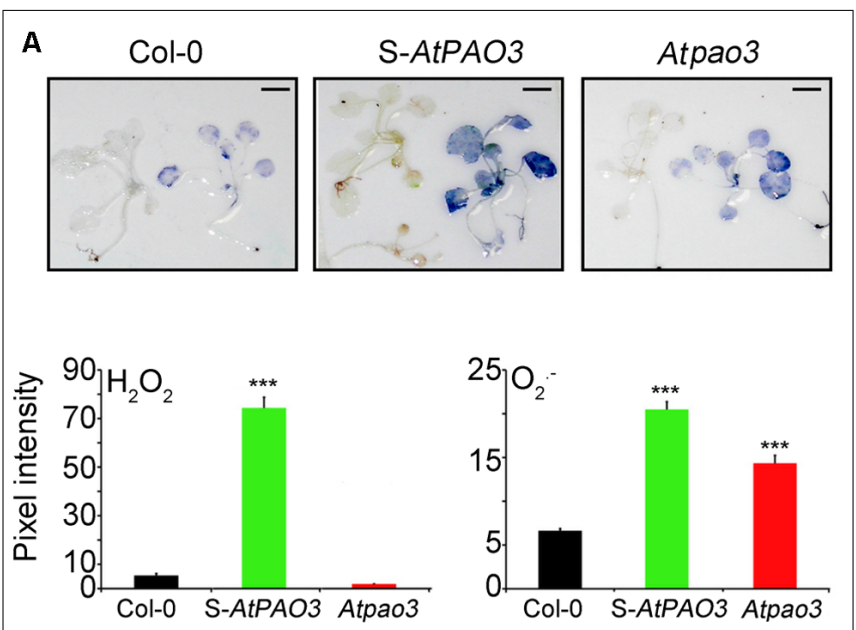

B

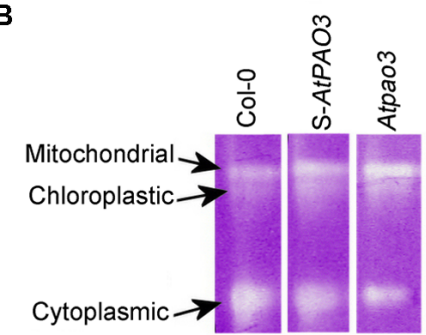

C

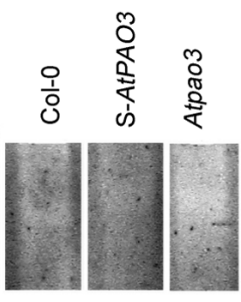

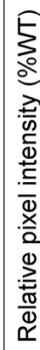
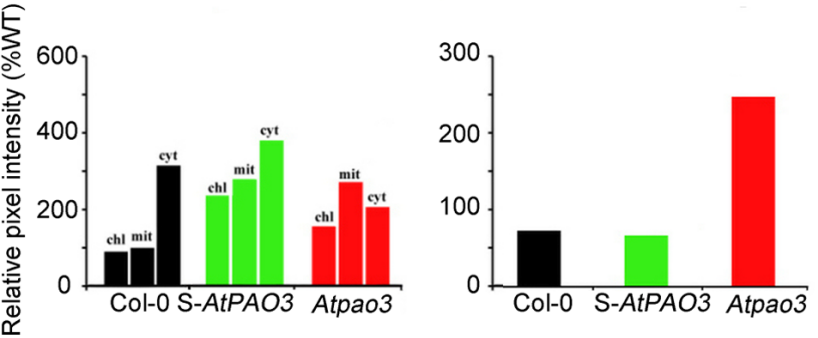

FIGURE 4 | In situ ROS in WT, S-AtPAO3, and Atpao3 Arabidopsis plants. (A) In situ ROS detection in WT, S-AtPAO3 and Atpao3 plants. Data are from a single representative experiment, repeated three times, and densitometric analysis. Data are the means of three different positions on a leave. Asterisks indicate statistical significant differences from the Col-0 ( ${ }^{* *} P<0.001$ ). Scale bars, $2.8 \mathrm{~cm}$. (B) Native electrophoresis and activity staining of SOD and densitometric analysis of isoenzymes. (C) Native electrophoresis and activity staining of APX and densitometric analysis. for studying the differential effects of $\mathrm{H}_{2} \mathrm{O}_{2}$ and $\mathrm{O}_{2}^{\bullet-}$ in oxygen consumption.

Next, we examined a possible contribution of the antioxidant machinery in the observed differences in ROS levels in $\mathrm{S}-A t P A O 3$ and Atpao3 plants. We determined the contribution of SOD and APX, a well-established $\mathrm{H}_{2} \mathrm{O}_{2}$ scavenger, in the observed differences, between Col-0, S-AtPAO3 and Atpao3 in $\mathrm{H}_{2} \mathrm{O}_{2}$ and $\mathrm{O}_{2}^{\bullet-}$ levels. Accumulation of $\mathrm{O}_{2}^{\bullet-}$ in $\mathrm{S}-A t P A O 3$ and Atpao3 plants coincided with increased SOD activity in mitochondria and chloroplasts (Figure 4B). In contrast, APX was elevated in the Atpao3, but reduced in S-AtPAO3 plants (Figure 4C). APX has a high affinity for $\mathrm{H}_{2} \mathrm{O}_{2}$ and therefore is downregulated at higher levels of $\mathrm{H}_{2} \mathrm{O}_{2}$ (Asada, 1992), which perhaps can explain the decrease of APX observed in S-AtPAO3 plants, with increased $\mathrm{H}_{2} \mathrm{O}_{2}$ levels. These results suggest that at least APX and SOD mirror the changes of ROS levels observed in S-AtPAO3 and Atpao3.

\section{DEREGULATION OF ATPA03 RESULTS TO CHANGES IN OXYGEN CONSUMPTION RATE}

Overall the data presented so far support the role of Spd as an inducer of mitochondrial respiration via the NADPH-oxidase generated $\mathrm{O}_{2}^{\bullet-}$ in Col-0 plants. This response is alleviated mostly by the action of the NADPH-oxidase blocker, DPI. Furthermore, loss-of-function mutant plants for the peroxisomal AtPAO3 gene accumulate $\mathrm{O}_{2}^{\bullet-}$, but not $\mathrm{H}_{2} \mathrm{O}_{2}$ in contrast to S-AtPAO3 overexpressing plants, which accumulate both $\mathrm{O}_{2}^{\bullet-}$ and $\mathrm{H}_{2} \mathrm{O}_{2}$. Considering the above, we determined the oxygen consumption rate in the S-AtPAO3 transgenics and the Atpao3 mutants to test whether the differential accumulation of ROS in the two genotypes leads to altered oxygen consumption. Indeed, the three tested genotypes exhibited notable differences in their capacity to consume oxygen (Figure 5A). The Atpao3 plants exhibited the highest rate of oxygen consumption among the tested plants, showing a 2.7-fold increase over the Col-0 plants and a 4.3-fold increase over the $\mathrm{S}-A t P A O 3$ plants. Interestingly, the increase in oxygen consumption of Atpao3 plants resembled the effect of exogenous Spd in Col-0 plants.

Next, we examined whether the increase in oxygen consumption of Atpao3 plants is $\mathrm{O}_{2}^{\bullet-}$-dependent. To test this, we treated Atpao 3 with DPI, and as a control, we treated Col-0 plants simultaneously with Spd and DPI (Figure 5A). Treatment of Atpao3 plants with DPI reduced the respiratory activity to the control levels, suggesting that increase of oxygen consumption in Atpao3 plants depends on the production of $\mathrm{O}_{2}^{\bullet-}$ by NADPH-oxidase. Similarly, Spd plus DPI treated Col-0 plants showed similar oxygen consumption rate to the untreated Col-0 plants, producing an effect equivalent to the DPI-induced decrease in the $\mathrm{O}_{2}^{\bullet-}$ accumulation reported earlier.

We hypothesized that the increase observed in the Atpao3 plants could be due to an increased contribution of the AOX pathway. To test this, we used the AOX pathway blocker SHAM. Indeed, application of SHAM to the Atpao3 plants exerted a dramatic decrease in the oxygen consumption rate, suggesting the participation of the AOX pathway in the $\mathrm{O}_{2}^{\bullet-}$-induced oxygen consumption (Figure 5A). In addition, the levels of the immunoreactive AOX protein in Atpao3 were significantly higher compared to the rest 


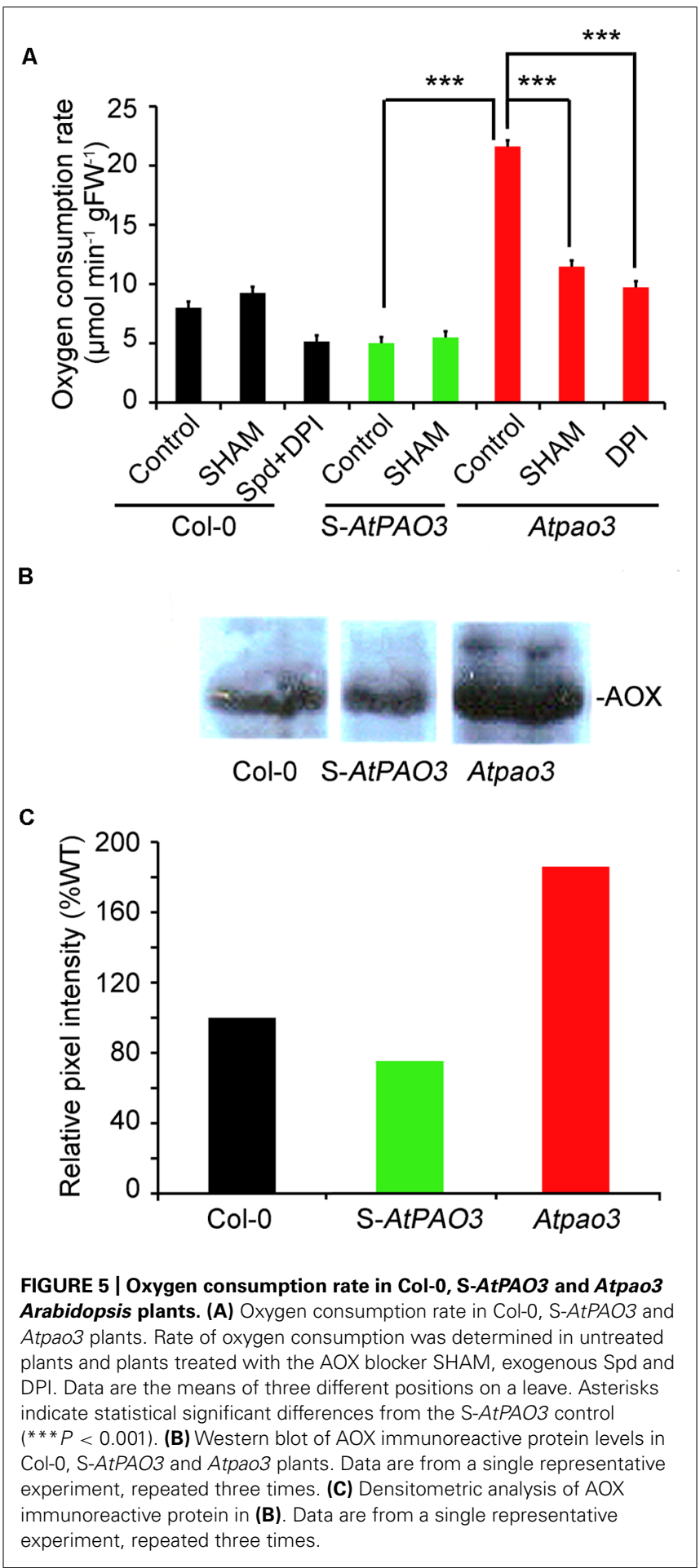

of the tested plants (Figures 5B,C). These results suggest that the $\mathrm{O}_{2}^{\bullet-}$-dependent increase of oxygen consumption in Atpao3 plants is exerted through the AOX pathway.

\section{DISCUSSION}

Exogenous Spm application to tobacco plants leads to mitochondrial dysfunction and to transcriptional activation of the AOX pathway, while small molecular weight antioxidants efficiently attenuate this induction, suggesting a possible involvement of ROS in this Spm-signaling pathway (Takahashi et al., 2003). A long standing notion proposed that PA oxidation results in induction of signaling cascades through $\mathrm{H}_{2} \mathrm{O}_{2}$, since $\mathrm{H}_{2} \mathrm{O}_{2}$ is a direct product of PA oxidation (Moschou et al., 2008b). However, recent evidence suggests that other ROS types may as well contribute to PA-dependent signaling cascades and that the PAs-ROS crosstalk stretches beyond $\mathrm{H}_{2} \mathrm{O}_{2}$ (Zepeda-Jazo et al., 2011; Velarde-Buendia et al., 2012).

In this work, application of exogenous PAs to Col-0 Arabidopsis plants stimulated the oxygen consumption rate; the stronger effect was exerted by Spd. Exogenous application of Spd is expected to increase $\mathrm{H}_{2} \mathrm{O}_{2}$ content through the PA oxidation/backconvertion pathway (Yoda et al., 2003; Moschou et al., 2008b). Therefore, we hypothesized that this product could be responsible for the increase in oxygen consumption. Surprisingly, $\mathrm{H}_{2} \mathrm{O}_{2}$ scavenging did not significantly attenuate the PA-dependent oxygen increase. On the other hand, exogenous SOD or DPI ameliorated the oxygen increase, caused by the exogenous Spd application. This denotes that the increase in oxygen consumption relies on $\mathrm{O}_{2}^{\bullet-}$ production, and suggests that exogenous PA induces $\mathrm{O}_{2}^{\bullet-}$ production by NADPH-oxidase intriguingly, DPI exerts a stronger effect than SOD. This may be due to the fact that SOD is expected to scavenge intercellular $\mathrm{O}_{2}^{\bullet-}$ produced by NADPH-oxidase, giving rise to $\mathrm{H}_{2} \mathrm{O}_{2}$, while DPI is a plasma membrane permeable suicidal NADPH-oxidase inhibitor, that could efficiently prevent production of higher amount of $\mathrm{O}_{2}^{\bullet-}$. Surprisingly, CAT mimicked the DPI effect. Nevertheless, it should be noted that recent evidence suggests that CAT participates in the induction of cell death (Hackenberg et al., 2013), therefore perplexing the interpretation of the data obtained with the use of CAT. ASA, on the other hand, did not alleviate oxygen consumption increase. It should be noted that ASA is a reducing agent, thereby directly affecting the ETC, and scavenges both $\mathrm{O}_{2}^{\bullet-}$ and $\mathrm{H}_{2} \mathrm{O}_{2}$ (Foyer and Noctor, 2011). These results suggest that the PA-derived oxygen consumption increase depends mostly on $\mathrm{O}_{2}^{\bullet-}$ production by the PA-induced NADPH-oxidase.

Exogenous PA at relatively high concentrations stimulated production of $\mathrm{O}_{2}^{\bullet-}$ in human neutrophils (Guarnieri et al., 1987). In our study, exogenous application of Spd in Arabidopsis increased the content of $\mathrm{H}_{2} \mathrm{O}_{2}$ produced through $\mathrm{PAO}$, as previously suggested for other plant species (Yoda et al., 2006; Wu et al., 2010; Moschou and Roubelakis-Angelakis, 2011; Tisi et al., 2011). Nevertheless, exogenous Spd induced a significant increase in the levels of $\mathrm{O}_{2}^{\bullet-}$ along with an increase in NADPH-oxidase activity. Interestingly, previous studies suggested that Spd induces autophagy (self-consumption) in non-plant models and is an important surveillance mechanism that rather restricts ROS production (Eisenberg et al., 2009). In accordance, during protoplast isolation from tobacco (Papadakis and Roubelakis-Angelakis, 2005), induction of NADPH-oxidase and the concomitant production of $\mathrm{O}_{2}^{\bullet-}$ was highly suppressed by PAs. This discrepancy between our current and previous work could be due to the fact that in Papadakis and Roubelakis-Angelakis paper, PAs were added to the protoplasts and then NADPH-oxidase was purified 
and assayed. On the contrary, in this study PAs were added exogenously and NADPH-oxidase assessment was performed by an in-gel assay omitting further purification steps. This allows us to hypothesize that exogenous PAs may antagonize for $\mathrm{Ca}^{2+}$ in $\mathrm{NADPH}$-oxidase preparations. Calcium is required for $\mathrm{NADPH}-$ oxidase activation. Therefore, we assume that NADPH-oxidase cannot accommodate $\mathrm{Ca}^{2+}$ in the presence of PAs on its binding. In addition, in the previous study $\mathrm{O}_{2}^{\bullet-}$ content was determined by a chemiluminescence assay, while in this work we used an in situ detection protocol, which seems to be a more accurate and reliable method (Song et al., 2006). Therefore, PAs and especially Spd seem to positively affect NADPH-oxidase in planta, unlike in in vitro systems. In addition, a species-related differential effect on NADPH-oxidase of PA cannot be ruled out (tobacco versus Arabidopsis).

From the aforementioned, it is conceivable that production of $\mathrm{O}_{2}^{\bullet-}$ may depend on a PAO system. There are two main PA oxidation regimes: an apoplastic and an intracellular one. Several plant species, especially monocots, possess the ability to oxidize higher PAs in their apoplastic compartments. The oxidative reaction is executed by DAOs and PAOs residing in this compartment. However, the former enzymes show low affinity for higher PAs such as Spd. Notably, apoplastic PAOs in Arabidopsis are missing. There are five genes encoding for PAOs in Arabidopsis. The inducible AtPAO1 (Tavladoraki et al., 2006) and constitutively expressed AtPAO5 (Ahou et al., 2014) encode for cytoplasmic enzymes, oxidizing Spm, while AtPAO2, 3, 4 encode peroxisomal proteins (Kamada-Nobusada et al., 2008; Moschou et al., 2008c), oxidizing Spd (AtPAO2, 3) and Spm (AtPAO2,3,4). On the other hand, in Arabidopsis there are ten genes encoding DAOs, four of which have been characterized. One of them is an apoplastic enzyme; however, six remain to be characterized (Moschou et al., 2013; Planas-Portell et al., 2013). These suggest that most likely the contribution of the apoplast to the Spd-dependent production of $\mathrm{O}_{2}^{\bullet-}$ is rather minimal in Arabidopsis.

To further examine whether intracellular PAOs are responsible for inducing production of $\mathrm{O}_{2}^{\bullet-}$, we employed genetic means. The best characterized so far enzymatic activity that oxidizes mostly Spd and to a smaller extent Spm in Arabidopsis is that of the peroxisomal AtPAO3 (Moschou et al., 2008c; Fincato et al., 2012). In mammals and plants, PA oxidation has been implicated in the execution of PCD (Yoda et al., 2003; Tavladoraki et al., 2006; Moschou and Roubelakis-Angelakis, 2013). It has been exemplified that there is a direct relationship between PCD and the levels of cytotoxic PA catabolic products, i.e., $\mathrm{H}_{2} \mathrm{O}_{2}$ and aminoaldehydes. For example, during Helicobacter pylori infection that contributes to gastric cancer, $\mathrm{PA}$-derived $\mathrm{H}_{2} \mathrm{O}_{2}$ coincides with $\mathrm{PCD}$ induction (Chaturvedi et al., 2004). However, PA-derived $\mathrm{H}_{2} \mathrm{O}_{2}$ seems to be a double-edged sword since oxidation by SMO could perhaps contribute to the eradication of tumor cells (Babbar et al., 2007). In tobacco, overexpression of apoplastic PAO is accompanied by premature cell death of xylem tissue (Tisi et al., 2011). Interestingly, exogenous supply of Spd to maize root tips highly expressing $P A O$ alters cell cycle distribution, toward quiescence and induces PCD (Tisi etal., 2011). In addition, premature cell death of xylem hinders the proper differentiation of the secondary cell wall, which is normally deposited before PCD induction in xylem.
Importantly, a $\mathrm{H}_{2} \mathrm{O}_{2}$ scavenger partially ameliorates Spd-induced effects. In addition, 4-aminobutanal which is an additional oxidation product of Spd, failed to mimic Spd effects, indicating that PAO-derived $\mathrm{H}_{2} \mathrm{O}_{2}$ is sufficient to induce PCD independently of aminoaldehydes.

In contrast to the previous, the PA backconversion pathway seems to have completely distinct functions, which remain largely elusive. It was shown that AtPAO3 is an important component of pollen tube elongation (Wu et al., 2010). More specifically, AtPAO3 generates $\mathrm{H}_{2} \mathrm{O}_{2}$ which positively affects the permeability of a plasma membrane-residing $\mathrm{Ca}^{2+}$ influx channel. As a result, the intracellular concentration of $\mathrm{Ca}^{2+}$ increases, thereby promoting pollen tube elongation. In loss-of-function Atpao3 reduction of pollen tube elongation, and in a physiological context reduced fertility was evident. In addition, a role for the PA backconversion pathway was hypothesized with respect to dehydration response of Arabidopsis (Alcazar et al., 2011a). The putative paralog of AtPAO3 gene, AtPAO2 is upregulated by drought stress in a similar fashion as $R D 29 A$ and $R D 22$.

A number of PAOs have been implicated in the PA backconversion pathway in Arabidopsis and, unlike in mammals, plant PAOs did not require acetylated derivatives (Moschou et al., 2008c). We observed that plants overexpressing AtPAO3 showed increased content of $\mathrm{H}_{2} \mathrm{O}_{2}$ consistent with its role in PAs oxidation. Surprisingly, this $\mathrm{H}_{2} \mathrm{O}_{2}$ production led to a significant $\mathrm{O}_{2}^{\bullet-}$ increase, while Atpao3 mutants showed reduced levels of $\mathrm{H}_{2} \mathrm{O}_{2}$ but increased $\mathrm{O}_{2}^{\bullet-}$. This implies that loss of AtPAO3 caused an increment of $\mathrm{O}_{2}^{\bullet-}$ versus $\mathrm{H}_{2} \mathrm{O}_{2}$. In animal cells, ROS have also been shown to play an important role in maintaining the balance between cell proliferation and differentiation. A redox-dependent signaling pathway controls the induction of cell division through the regulation of cyclinD1 expression (Burch and Heintz, 2005). Distribution of specific ROS appears to act as an important signal at the transcriptional and posttranscriptional levels during cellcycle progression (Menon and Goswami, 2007). In Drosophila, changing ROS balance can switch the status of hematopoietic cells from proliferation to differentiation (Owusu-Ansah and Banerjee, 2009). In Arabidopsis, it was shown that $\mathrm{O}_{2}^{\bullet-}$ accumulates primarily in the root meristematic zone, whereas $\mathrm{H}_{2} \mathrm{O}_{2}$ accumulates mainly in the elongation zone (Tsukagoshi et al., 2010). Moreover, it has been shown that Mn-SOD activity regulates cell-cycle progression through modulation of ROS levels, which control expression of both the cyclinB1 and cyclinD1 genes in mouse cells (Sarsour et al., 2008). The authors proposed that $\mathrm{O}_{2}^{\bullet-}$ regulates the proliferative cycle, whereas $\mathrm{H}_{2} \mathrm{O}_{2}$ induces quiescence and differentiation. Therefore, in the root elongation zone, the ratio between $\mathrm{O}_{2}^{\bullet-}$ and $\mathrm{H}_{2} \mathrm{O}_{2}$ is decreased (Tsukagoshi et al., 2010).

In our study, AtPAO3 was shown to be an important factor for balancing $\mathrm{O}_{2}^{\bullet-}$ and $\mathrm{H}_{2} \mathrm{O}_{2}$. Increased levels of $\mathrm{O}_{2}^{\bullet-}$ versus $\mathrm{H}_{2} \mathrm{O}_{2}$ were detected in the absence of AtPAO3, perhaps due to the increased activity of APX, which scavenges $\mathrm{H}_{2} \mathrm{O}_{2}$. S-AtPAO3 plants show reduced expression of APX but increased expression of mitochondrial and chloroplastic SOD isoenzymes, while Atpao3 show significantly increased expression of APX, mitochondrial and chloroplastic SOD. Noteworthy, the increased isoenzymes are in proximity to peroxisomes. These changes are in accordance 
with the ROS levels detected in these plants. However, further studies are required to elucidate whether the increased/decreased expression of these antioxidants controls ROS levels or alternatively, whether ROS levels control the induction/reduction of these genes/enzymes. Although this may sound like a "chicken or the egg" question it merits careful examination to further understand the regulation of ROS homeostasis. We can speculate that similar regulation of the $\mathrm{O}_{2}^{--} / \mathrm{H}_{2} \mathrm{O}_{2}$ ratio takes place during other developmental transitions, apart the ones reported in the root (Tsukagoshi et al., 2010) like for example during pollen tube growth, which could contribute to the failure of Atpao3 pollen tube elongation (Wu et al., 2010).

Overexpression of SSAT in mice, an acetylase required to direct PAs in non-plant models toward the PAO pathway, leads to increased $\mathrm{H}_{2} \mathrm{O}_{2}$ and carbonyl content, and reduced SOD, CAT, and cyt CYP450 2E1 expression, responsible for xenobiotic metabolism. This suggests that transgenic mice are hypersensitive to stress, leading to cell death, and they also are sluggish and less hostile (Kaasinen et al., 2004). Interestingly, although SAtPAO3 plants accumulate significantly higher amounts of ROS, they do not show symptoms of chronic stress. Tobacco plants overexpressing apoplastic PAO exhibit increased SOD and CAT expression, which do not exert a protective effect, but rather this increased expression represents an attempt to scavenge surplus $\mathrm{H}_{2} \mathrm{O}_{2}$ produced by continuous PA oxidation. The previous suggests that as in animals, constitutive apoplastic PA oxidation in plants can lead to chronic oxidative stress (Moschou et al., 2008a).

On the contrary, the AtPAO3 backconversion pathway seems to have a completely different function. We show that Spd oxidation by AtPAO3 is required for a balanced respiration through the cyt-c and AOX pathways. Notably, overproduction of PAderived $\mathrm{H}_{2} \mathrm{O}_{2}$ in the $\mathrm{S}-A t P A O 3$ plants results in a small decrease of oxygen rate consumption, but not in induction of the AOX pathway. To the contrary, Atpao3 plants show increased oxygen consumption through the AOX pathway. Interestingly, this increase is attenuated by application of DPI, which specifically blocks $\mathrm{O}_{2}^{\bullet-}$ generation by NADPH-oxidase. It was reported that a microtubule associated kinesin and a mitochondrial channel are able to regulate the balance between cyt-c and AOX pathways (Yang et al., 2011). In addition, it has been hypothesized that the ratio of (singlet $\left.+\mathrm{O}_{2}^{\bullet-}\right) / \mathrm{H}_{2} \mathrm{O}_{2}$ determines PCD initiation during stress (Sabater and Martin, 2013). The previous allow us to propose that an increased ratio of $\mathrm{O}_{2}^{\bullet-} / \mathrm{H}_{2} \mathrm{O}_{2}$ leads to increased oxygen consumption through the AOX pathway. Likewise, it has been reported that $\mathrm{O}_{2}^{\bullet-}$ is sufficient to induce $A O X 1 a / b$ genes in rice ( $\mathrm{Li}$ et al., 2013). These results demonstrate that depletion of AtPAO3 leads to higher production of $\mathrm{O}_{2}^{\bullet-}$, which in turn activates the AOX pathway.

In conclusion, our results allow us to propose that AtPAO3 is required for balancing $\mathrm{O}_{2}^{\bullet-} / \mathrm{H}_{2} \mathrm{O}_{2}$ production. An imbalance of the $\mathrm{O}_{2}^{\bullet-}$ versus $\mathrm{H}_{2} \mathrm{O}_{2}$ production leads to activation of AOX pathway and increases oxygen consumption. The next critical step to advance our understanding on the role of PA backconversion, and its interplay and crosstalk with ROS will be the genetic dissection of PA backconverting pathways, and their molecular effectors.

\section{ACKNOWLEDGMENTS}

This work is implemented in the frame of ABISTOLE project KA3571 and the EU COSTFA1106 action.

\section{REFERENCES}

Ahou, A., Martignago, D., Alabdallah, O., Tavazza, R., Stano, P., Macone, A., et al. (2014). A plant spermine oxidase/dehydrogenase regulated by the proteasome and polyamines. J. Exp. Bot. doi: 10.1093/jxb/eru016 [Epub ahead of print].

Alcazar, R., Bitrian, M., Bartels, D., Koncz, C., Altabella, T., and Tiburcio, A. F. (2011a). Polyamine metabolic canalization in response to drought stress in Arabidopsis and the resurrection plant Craterostigma plantagineum. Plant Signal. Behav. 6, 243-250. doi: 10.4161/psb.6.2.14317

Alcazar, R., Cuevas, J. C., Planas, J., Zarza, X., Bortolotti, C., Carrasco, P., et al. (2011b). Integration of polyamines in the cold acclimation response. Plant Sci. 180, 31-38. doi: 10.1016/j.plantsci.2010.07.022

Andronis, E. A., and Roubelakis-Angelakis, K. A. (2010). Short-term salinity stress in tobacco plants leads to the onset of animal-like PCD hallmarks in planta in contrast to long-term stress. Planta 231, 437-448. doi: 10.1007/s00425-0091060-x

Angelini, R., Cona, A., Federico, R., Fincato, P., Tavladoraki, P., and Tisi, A. (2010). Plant amine oxidases "on the move": an update. Plant Physiol. Biochem. 48, 560-564. doi: 10.1016/j.plaphy.2010.02.001

Asada, K. (1992). Ascorbate peroxidase-a hydrogen peroxide-scavenging enzyme in plants. Physiol. Plant. 85, 235-241. doi: 10.1111/j.1399-3054.1992.tb0 4728.x

Atkin, O. K., Zhang, Q., and Wiskich, J. T. (2002). Effect of temperature on rates of alternative and cytochrome pathway respiration and their relationship with the redox poise of the quinone pool. Plant Physiol. 128, 212-222. doi: 10.1104/pp.010326

Babbar, N., Murray-Stewart, T., and Casero, R. A. Jr. (2007). Inflammation and polyamine catabolism: the good, the bad and the ugly. Biochem. Soc. Trans. 35, 300-304. doi: 10.1042/BST0350300

Baron, K., and Stasolla, C. (2008). The role of polyamines during in vivo and in vitro development. In Vitro Cell Dev. Biol. 44, 384-395. doi: 10.1007/s11627-0089176-4

Beauchamp, C., and Fridovich, I. (1971). Superoxide dismutase: improved assays and an assay applicable to acrylamide gels. Anal. Biochem. 44, 276-287. doi: 10.1016/0003-2697(71)90370-8

Burch, P. M., and Heintz, N. H. (2005). Redox regulation of cell-cycle re-entry: cyclin D1 as a primary target for the mitogenic effects of reactive oxygen and nitrogen species. Antioxid. Redox Signal. 7, 741-751. doi: 10.1089/ars.2005. 7.741

Carter, C., Healy, R., O’Tool, N. M., Naqvi, S. M. S., Ren, G., Park, S., et al. (2007). Tobacco nectaries express a novel NADPH oxidase implicated in the defense of floral reproductive tissues against microorganisms. Plant Physiol. 143, 389-399. doi: $10.1104 /$ pp.106.089326

Chattopadhyay, M. K., Tabor, C. W., and Tabor, H. (2006). Polyamine deficiency leads to accumulation of reactive oxygen species in a spe2Delta mutant of Saccharomyces cerevisiae. Yeast 23, 751-761. doi: 10.1002/yea.1393

Chaturvedi, R., Cheng, Y. L., Asim, M., Bussiere, F. I., Xu, H. X., Gobert, A. P., et al. (2004). Induction of polyamine oxidase 1 by Helicobacter pylori causes macrophage apoptosis by hydrogen peroxide release and mitochondrial membrane depolarization. J. Biol. Chem. 279, 40161-40173. doi: 10.1074/jbc.M401370200

Cohen, S. S. (1998). A Guide to Polyamines. Oxford: Oxford University Press.

Dikalov, S., Nazarewicz, R., Panov, A., Harrison, D. G., and Dikalova, A. (2011). Crosstalk between mitochondrial ROS and NADPH oxidases in cardiovascular and degenerative diseases: application of mitochondria-targeted antioxidants. Free Radic. Biol. Med. 51, S85-S86. doi: 10.1016/j.freeradbiomed.2011. 10.397

Eisenberg, T., Knauer, H., Schauer, A., Buttner, S., Ruckenstuhl, C., CarmonaGutierrez, D., et al. (2009). Induction of autophagy by spermidine promotes longevity. Nat. Cell Biol. 11, 1305-1314. doi: 10.1038/Ncb1975

Fincato, P., Moschou, P. N., Ahou, A., Angelini, R., Roubelakis-Angelakis, K. A., Federico, R., et al. (2012). The members of Arabidopsis thaliana PAO gene family exhibit distinct tissue- and organ-specific expression pattern during seedling growth and flower development. Amino Acids 42, 831-841. doi: 10.1007/s00726-011-0999-7 
Fincato, P., Moschou, P. N., Spedaletti, V., Tavazza, R., Angelini, R., Federico, R., et al. (2011). Functional diversity inside the Arabidopsis polyamine oxidase gene family. J. Exp. Bot. 62, 1155-1168. doi: 10.1093/jxb/erq341

Foyer, C. H., and Noctor, G. (2011). Ascorbate and glutathione: the heart of the redox hub. Plant Physiol. 155, 2-18. doi: 10.1104/pp.110.16756 155/1/2

Guarnieri, C., Georgountzos, A., Caldarera, I., Flamigni, F., and Ligabue, A. (1987). Polyamines stimulate superoxide production in human neutrophils activated by N-fMet-Leu-Phe but not by phorbol myristate acetate. Biochim. Biophys. Acto 930, 135-139. doi: 10.1016/0167-4889(87)90024-3

Hackenberg, T., Juul, T., Auzina, A., Gwizdz, S., Malolepszy, A., Van Der Kelen, K., et al. (2013). Catalase and NO CATALASE ACTIVITY1 promote autophagy-dependent cell death in Arabidopsis. Plant Cell 25, 4616-4626. doi: 10.1105/tpc.113.117192

Jabs, T., Dietrich, R. A., and Dangl, J. L. (1996). Initiation of runaway cell death in an Arabidopsis mutant by extracellular superoxide. Science 273, 1853-1856. doi: $10.1126 /$ science. 273.5283 .1853

Kaasinen, S. K., Oksman, M., Alhonen, L., Tanila, H., and Janne, J. (2004). Spermidine/spermine N1-acetyltransferase overexpression in mice induces hypoactivity and spatial learning impairment. Pharmacol. Biochem. Behav. 78, 35-45. doi 10.1016/j.pbb.2004.02.001

Kamada-Nobusada, T., Hayashi, M., Fukazawa, M., Sakakibara, H., and Nishimura, M. (2008). A putative peroxisomal polyamine oxidase, AtPAO4, is involved in polyamine catabolism in Arabidopsis thaliana. Plant Cell Physiol. 49, 1272-1282. doi: $10.1093 / \mathrm{pcp} / \mathrm{pcn} 114$

Kwak, J. M., Mori, I. C., Pei, Z. M., Leonhardt, N., Torres, M. A., Dangl, J. L., et al. (2003). NADPH oxidase AtrbohD and AtrbohF genes function in ROS-dependent ABA signaling in Arabidopsis. EMBO J. 22, 2623-2633. doi 10.1093/Emboj/Cdg277

Li, C. R., Liang, D. D., Li, J., Duan, Y. B., Li, H., Yang, Y. C., et al. (2013). Unravelling mitochondrial retrograde regulation in the abiotic stress induction of rice ALTERNATIVE OXIDASE 1 genes. Plant Cell Environ. 36, 775-788. doi: 10.1111/Pce. 12013

Marco, F., Alcazar, R., Tiburcio, A. F., and Carrasco, P. (2011). Interactions between polyamines and abiotic stress pathway responses unraveled by transcriptome analysis of polyamine overproducers. OMICS 15, 775-781. doi: 10.1089/omi.2011.0084

Mattoo, A. K., Sobolev, A. P., Neelam, A., Goyal, R. K., Handa, A. K., and Segre, A. L. (2006). Nuclear magnetic resonance spectroscopy-based metabolite profiling of transgenic tomato fruit engineered to accumulate spermidine and spermine reveals enhanced anabolic and nitrogen-carbon interactions. Plant Physiol. 142, 1759-1770. doi: 10.1104/pp.106.084400

Menon, S. G., and Goswami, P. C. (2007). A redox cycle within the cell cycle: ring in the old with the new. Oncogene 26, 1101-1109. doi: 10.1038/sj.onc.12 09895

Møller, S. G., and McPherson, M. J. (1998). Developmental expression and biochemical analysis of the Arabidopsis ataol gene encoding an $\mathrm{H}_{2} \mathrm{O}_{2}$-generating diamine oxidase. Plant J. 13, 781-791. doi: 10.1046/j.1365-313X.1998.00080.x

Moschou, P. N., Delis, I. D., Paschalidis, K. A., and Roubelakis-Angelakis, K. A (2008a). Transgenic tobacco plants overexpressing polyamine oxidase are not able to cope with oxidative burst generated by abiotic factors. Physiol. Plant. 133, 140-156. doi: 10.1111/j.1399-3054.2008.01049.x

Moschou, P. N., Paschalidis, K. A., Delis, I. D., Andriopoulou, A. H., Lagiotis, G. D., Yakoumakis, D. I., et al. (2008b). Spermidine exodus and oxidation in the apoplast induced by abiotic stress is responsible for $\mathrm{H}_{2} \mathrm{O}_{2}$ signatures that direct tolerance responses in tobacco. Plant Cell 20, 1708-1724. doi: 10.1105/tpc.108.059733

Moschou, P. N., Sanmartin, M., Andriopoulou, A. H., Rojo, E., Sanchez-Serrano, J. J., and Roubelakis-Angelakis, K. A. (2008c). Bridging the gap between plant and mammalian polyamine catabolism: a novel peroxisomal polyamine oxidase responsible for a full back-conversion pathway in Arabidopsis. Plant Physiol. 147, 1845-1857. doi: 10.1104/pp.108.123802

Moschou, P. N., and Roubelakis-Angelakis, K. A. (2011). Characterization, assay, and substrate specificity of plant polyamine oxidases. Methods Mol. Biol. 720, 183-194. doi: 10.1007/978-1-61779-034-8_11

Moschou, P. N., and Roubelakis-Angelakis, K. A. (2013). Polyamines and programmed cell death. J. Exp. Bot. doi: 10.1093/jxb/ert373 [Epub ahead of print].

Moschou, P. N., Smertenko, A. P., Minina, E. A., Fukada, K., Savenkov, E. I., Robert, S., et al. (2013). The caspase-related protease separase (EXTRA SPINDLE POLES) regulates cell polarity and cytokinesis in Arabidopsis. Plant Cell 25, 2171-2186. doi: 10.1105/tpc.113.113043

Moschou, P. N., Wu, J., Cona, A., Tavladoraki, P., Angelini, R., and RoubelakisAngelakis, K. A. (2012). The polyamines and their catabolic products are significant players in the turnover of nitrogenous molecules in plants. J. Exp. Bot. 63, 5003-5015. doi: 10.1093/jxb/ers202

Muller, F. L., Liu, Y., and Van Remmen, H. (2004). Complex III releases superoxide to both sides of the inner mitochondrial membrane. J. Biol. Chem. 279, 49064 49073. doi: 10.1074/jbc.M407715200

Murashige, T., and Skoog, F. (1962). A revised medium for rapid growth and bio-assays with tobacco tissue cultures. Physiol. Plant. 15, 473-497. doi: 10.1111/j.1399-3054.1962.tb08052.x

Owusu-Ansah, E., and Banerjee, U. (2009). Reactive oxygen species prime Drosophila haematopoietic progenitors for differentiation. Nature 461, 537-541. doi: 10.1038/Nature08313

Papadakis, A. K., and Roubelakis-Angelakis, K. A. (2005). Polyamines inhibit NADPH oxidase-mediated superoxide generation and putrescine prevents programmed cell death induced by polyamine oxidase-generated hydrogen peroxide. Planta 220, 826-837. doi: 10.1007/s00425-004-1400-9

Paschalidis, K. A., and Roubelakis-Angelakis, K. A. (2005a). Sites and regulation of polyamine catabolism in the tobacco plant. Correlations with cell division/expansion, cell cycle progression, and vascular development. Plant Physiol. 138, 2174-2184. doi: 10.1104/pp.105.063941

Paschalidis, K. A., and Roubelakis-Angelakis, K. A. (2005b). Spatial and temporal distribution of polyamine levels and polyamine anabolism in different organs/tissues of the tobacco plant. Correlations with age, cell division/expansion, and differentiation. Plant Physiol. 138, 142-152. doi: 10.1104/pp.104. 055483

Pitzschke, A., Forzani, C., and Hirt, H. (2006). Reactive oxygen species signaling in plants. Antioxid. Redox Signal. 8, 1757-1764. doi: 10.1089/ars.2006.8.1757

Planas-Portell, J., Gallart, M., Tiburcio, A. F., and Altabella, T. (2013). Coppercontaining amine oxidases contribute to terminal polyamine oxidation in peroxisomes and apoplast of Arabidopsis thaliana. BMC Plant Biol. 13:109. doi: 10.1186/1471-2229-13-109

Rao, M. V., Hale, B. A., and Ormrod, D. P. (1995). Amelioration of ozone-induced oxidative damage in wheat plants grown under high-carbon dioxide - role of antioxidant enzymes. Plant Physiol. 109, 421-432.

Sabater, B., and Martin, M. (2013). Hypothesis: increase of the ratio singlet oxygen plus superoxide radical to hydrogen peroxide changes stress defense response to programmed leaf death. Front. Plant Sci. 4:479. doi: 10.3389/fpls.2013. 00479

Sagi, M., Davydov, O., Orazova, S., Yesbergenova, Z., Ophir, R., Stratmann, J. W., et al. (2004). Plant respiratory burst oxidase homologs impinge on wound responsiveness and development in Lycopersicon esculentum. Plant Cell 16, 616628. doi: 10.1105/Tpc.019398

Sarsour, E. H., Venkataraman, S., Kalen, A. L., Oberley, L. W., and Goswami, P. C. (2008). Manganese superoxide dismutase activity regulates transitions between quiescent and proliferative growth. Aging Cell 7, 405-417. doi: 10.1111/j.14749726.2008.00384.x

Segal, A. W., and Abo, A. (1993). The biochemical basis of the NADPH oxidase of phagocytes. Trends Biochem. Sci. 18, 43-47. doi: 10.1016/0968-0004(93)90051-N Song, C. J., Steinebrunner, I., Wang, X. Z., Stout, S. C., and Roux, S. J. (2006). Extracellular ATP induces the accumulation of superoxide via NADPH oxidases in Arabidopsis. Plant Physiol. 140, 1222-1232. doi: 10.1104/pp.105.073072

Suzuki, N., Miller, G., Salazar, C., Mondal, H. A., Shulaev, E., Cortes, D. F., et al. (2013). Temporal-spatial interaction between reactive oxygen species and abscisic acid regulates rapid systemic acclimation in plants. Plant Cell 25, 3553-3569. doi: $10.1105 /$ tpc. 113.114595

Takahashi, T., and Kakehi, J. (2010). Polyamines: ubiquitous polycations with unique roles in growth and stress responses. Ann. Bot. 105, 1-6. doi: 10.1093/aob/mcp259

Takahashi, Y., Berberich, T., Miyazaki, A., Seo, S., Ohashi, Y., and Kusano, T. (2003). Spermine signalling in tobacco: activation of mitogen-activated protein kinases by spermine is mediated through mitochondrial dysfunction. Plant J. 36, 820-829. doi: 10.1046/j.1365-313X.2003.01923.x

Tavladoraki, P., Rossi, M. N., Saccuti, G., Perez-Amador, M. A., Polticelli, F., Angelini, R., et al. (2006). Heterologous expression and biochemical characterization of a polyamine oxidase from Arabidopsis involved in polyamine back conversion. Plant Physiol. 141, 1519-1532. doi: 10.1104/pp.106.080911 
Thordal-Christensen, H., Zhang, Z. G., Wei, Y. D., and Collinge, D. B. (1997). Subcellular localization of $\mathrm{H}_{2} \mathrm{O}_{2}$ in plants. $\mathrm{H}_{2} \mathrm{O}_{2}$ accumulation in papillae and hypersensitive response during the barley-powdery mildew interaction. Plant J. 11, 1187-1194. doi: 10.1046/j.1365-313X.1997.11061187.x

Tisi, A., Federico, R., Moreno, S., Lucretti, S., Moschou, P. N., Roubelakis-Angelakis K. A., et al. (2011). Perturbation of polyamine catabolism can strongly affect root development and xylem differentiation. Plant Physiol. 157, 2258. doi $10.1104 /$ pp.111.900424

Torres, M. A., Jones, J. D. G., and Dangl, J. L. (2005). Pathogen-induced, NADPH oxidase-derived reactive oxygen intermediates suppress spread of cell death in Arabidopsis thaliana. Nat. Genet. 37, 1130-1134. doi: 10.1038/Ng1639

Toumi, I., Moschou, P. N., Paschalidis, K. A., Bouamama, B., Ben Salem-Fnayou, A. Ghorbel, A. W., et al. (2010). Abscisic acid signals reorientation of polyamine metabolism to orchestrate stress responses via the polyamine exodus pathway in grapevine. J. Plant Physiol. 167, 519-525. doi: 10.1016/j.jplph.2009. 10.022

Tsukagoshi, H., Busch, W., and Benfey, P. N. (2010). Transcriptional regulation of ROS controls transition from proliferation to differentiation in the root. Cell 143, 606-616. doi: 10.1016/j.cell.2010.10.020

Vacca, R. A., De Pinto, M. C., Valenti, D., Passarella, S., Marra, E., and De Gara, L. (2004). Production of reactive oxygen species, alteration of cytosolic ascorbate peroxidase, and impairment of mitochondrial metabolism are early events in heat shock-induced programmed cell death in tobacco Bright-Yellow 2 cells. Plant Physiol. 134, 1100-1112. doi: 10.1104/pp.103.035956

Velarde-Buendia, A. M., Shabala, S., Cvikrova, M., Dobrovinskaya, O., and Pottosin, I. (2012). Salt-sensitive and salt-tolerant barley varieties differ in the exten of potentiation of the ROS-induced $\mathrm{K}(+)$ efflux by polyamines. Plant Physiol. Biochem. 61, 18-23. doi: 10.1016/j.plaphy.2012.09.002

Vignais, P. V. (2002). The superoxide-generating NADPH oxidase: structural aspects and activation mechanism. Cell Mol. Life Sci. 59, 1428-1459. doi: 10.1007/s00018 002-8520-9

Wimalasekera, R., Tebartz, F., and Scherer, G. F. E. (2011). Polyamines, polyamine oxidases and nitric oxide in development, abiotic and biotic stresses. Plant Sci. 181, 593-603. doi: 10.1016/j.plantsci.2011.04.002

Wu, J., Shang, Z., Jiang, X., Moschou, P. N., Sun, W., Roubelakis-Angelakis, K. A., et al. (2010). Spermidine oxidase-derived $\mathrm{H}_{2} \mathrm{O}_{2}$ regulates pollen plasma membrane hyperpolarization-activated $\mathrm{Ca} 2+$-permeable channels and pollen tube growth. Plant J. 63, 1042-1053. doi: 10.1111/j.1365-313X.2010.04301.x
Yang, X. Y., Chen, Z. W., Xu, T., Qu, Z., Pan, X. D., Qin, X. H., et al. (2011). Arabidopsis kinesin KP1 specifically interacts with VDAC3, a mitochondrial protein, and regulates respiration during seed germination at low temperature. Plant Cell 23, 1093-1106. doi: 10.1105/tpc.110.082420

Yip, J. Y., and Vanlerberghe, G. C. (2001). Mitochondrial alternative oxidase acts to dampen the generation of active oxygen species during a period of rapid respiration induced to support a high rate of nutrient uptake. Physiol. Plant. 112, 327-333. doi: 10.1034/j.1399-3054.2001.1120305.x

Yoda, H., Hiroi, Y., and Sano, H. (2006). Polyamine oxidase is one of the key elements for oxidative burst to induce programmed cell death in tobacco cultured cells. Plant Physiol. 142, 193-206. doi: 10.1104/pp.106.080515

Yoda, H., Yamaguchi, Y., and Sano, H. (2003). Induction of hypersensitive cell death by hydrogen peroxide produced through polyamine degradation in tobacco plants. Plant Physiol. 132, 1973-1981. doi: 10.1104/pp.103.024737

Zepeda-Jazo, I., Velarde-Buendia, A. M., Enriquez-Figueroa, R., Bose, J., Shabala, S., Muniz-Murguia, J., et al. (2011). Polyamines interact with hydroxyl radicals in activating $\mathrm{Ca} 2+$ and $\mathrm{K}+$ transport across the root epidermal plasma membranes. Plant Physiol. 157, 2167-2180. doi: 10.1104/pp.111.179671

Conflict of Interest Statement: The authors declare that the research was conducted in the absence of any commercial or financial relationships that could be construed as a potential conflict of interest.

Received: 20 January 2014; paper pending published: 16 February 2014; accepted: 20 March 2014; published online: 03 April 2014.

Citation: Andronis EA, Moschou PN, Toumi I and Roubelakis-Angelakis KA (2014) Peroxisomal polyamine oxidase and NADPH-oxidase cross-talk for ROS homeostasis which affects respiration rate in Arabidopsis thaliana. Front. Plant Sci. 5:132. doi: 10.3389/fpls.2014.00132

This article was submitted to Plant Metabolism and Chemodiversity, a section of the journal Frontiers in Plant Science.

Copyright (C) 2014 Andronis, Moschou, Toumi and Roubelakis-Angelakis. This is an open-access article distributed under the terms of the Creative Commons Attribution License (CC BY). The use, distribution or reproduction in other forums is permitted, provided the original author(s) or licensor are credited and that the original publication in this journal is cited, in accordance with accepted academic practice. No use, distribution or reproduction is permitted which does not comply with these terms. 